
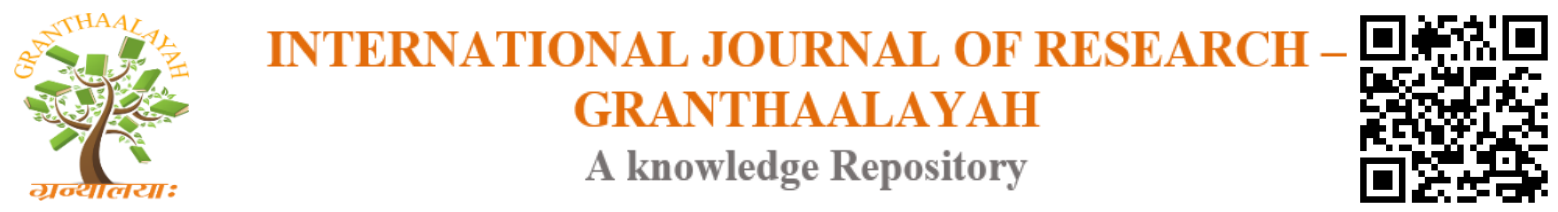

Science

\title{
ASSESSMENT OF FAILURE ON DRAINAGE STRUCTURES ALONG THE ETHIOPIAN NATIONAL RAILWAY LINE OF SEBETA-MIESO (CASE STUDY OF AKAKI RIVER CROSSING DRAINAGE STRUCTURE)
}

\author{
Yerosan Abera Hirpessa *1, Dr. Ing. Dereje Hailu ${ }^{2}$ \\ ${ }^{*}$ Civil Engineering Department, Ambo University, Ambo, Ethiopia, \\ ${ }^{2}$ Associate Professor at Addis Ababa Institute of Technology, Addis Ababa, Ethiopia
}

\begin{abstract}
A railway drainage system gives vital role for effective, efficient operation of rail track. This study worked on an assessment of railway drainage system problem along the Addis Ababa- Mieso railway line, specifically on Akaki rives crossing. It was done to check adequacy of hydraulic structure provided on Akaki River crossing by undertaking hydrologic and hydraulic analysis.

Hydrologic modeling of the Akaki catchment area was developed by HEC-GeoHMS program with the help of Arc-GIS and hydrologic analysis was computed by HEC-HMS program. The catchment land use, soil type, rainfall data, Akaki river stream flow data, etc were used to develop hydrological model. SCS unit hydrograph and flood frequency analysis methods were used to estimate instantaneous peak design discharge for 50 and 100 year return period. Model input parameters were calibrated and verified with observed flow data of the river at Akaki gauging station.

Hydraulic models were developed by HEC-RAS step-backwater to determine water-surface profiles for the bridge. Cross-sectional elevation data, hydraulic-structure geometries, roughness coefficients along with peak-discharge esti-mmated were used as input for the model.

Finally, adequacy of the bridge was evaluated where the bridge was hydraulically efficient over its design period.
\end{abstract}

Keywords: Akaki, Calibration; HEC-HMS; HEC-RAS; Hydrologic Models; New Railway Bridge; Objective Function; Simulation; Validation.

Cite This Article: Yerosan Abera Hirpessa, and Dr. Ing. Dereje Hailu. (2019). "ASSESSMENT OF FAILURE ON DRAINAGE STRUCTURES ALONG THE ETHIOPIAN NATIONAL RAILWAY LINE OF SEBETA-MIESO (CASE STUDY OF AKAKI RIVER CROSSING DRAINAGE STRUCTURE)." International Journal of Research - Granthaalayah, 7(9), 123-137. https://doi.org/10.29121/granthaalayah.v7.i9.2019.568.

\section{Introduction}

Paying attention to rail mode of transportation was one of the policies of the Federal Democratic Republic of Ethiopia in order to provide effective passenger and freight transport services. 
Currently about $2000 \mathrm{~km}$ of standard gauge railway infrastructure is under construction. Among this the Addis Ababa - Mieso-Dire Dawa - Dewale route is one of them.

In order to achieve the desired goals and objectives, it is important to deal with the safety, efficiency and effectiveness of each railway components. Adequate drainage system is essential in the design of railways and highway as it affects their serviceability and usable life [1]. The need to effectively remove surface water from all passengers, vehicle and rolling stock environments are essential for the network to operate safely and reliably. For the highway or railway designer, the primary focus of hydrology is the water that moves on the earth's surface and facility that can safely convey quantity of water [2].

This study is mainly concerned with the assessment of flooding problems associated with the Addis Ababa-Mieso railway drainage systems specifically at Akaki River crossing which might highly affect its functionality. Currently site observation shows that there is some failure on culvert structures, bridges and ditches has been noticed. Before the structures failure gets worse and cause loss of human life and resource, it is essential to conduct studies to identify problems, consequence of problems and give future works.
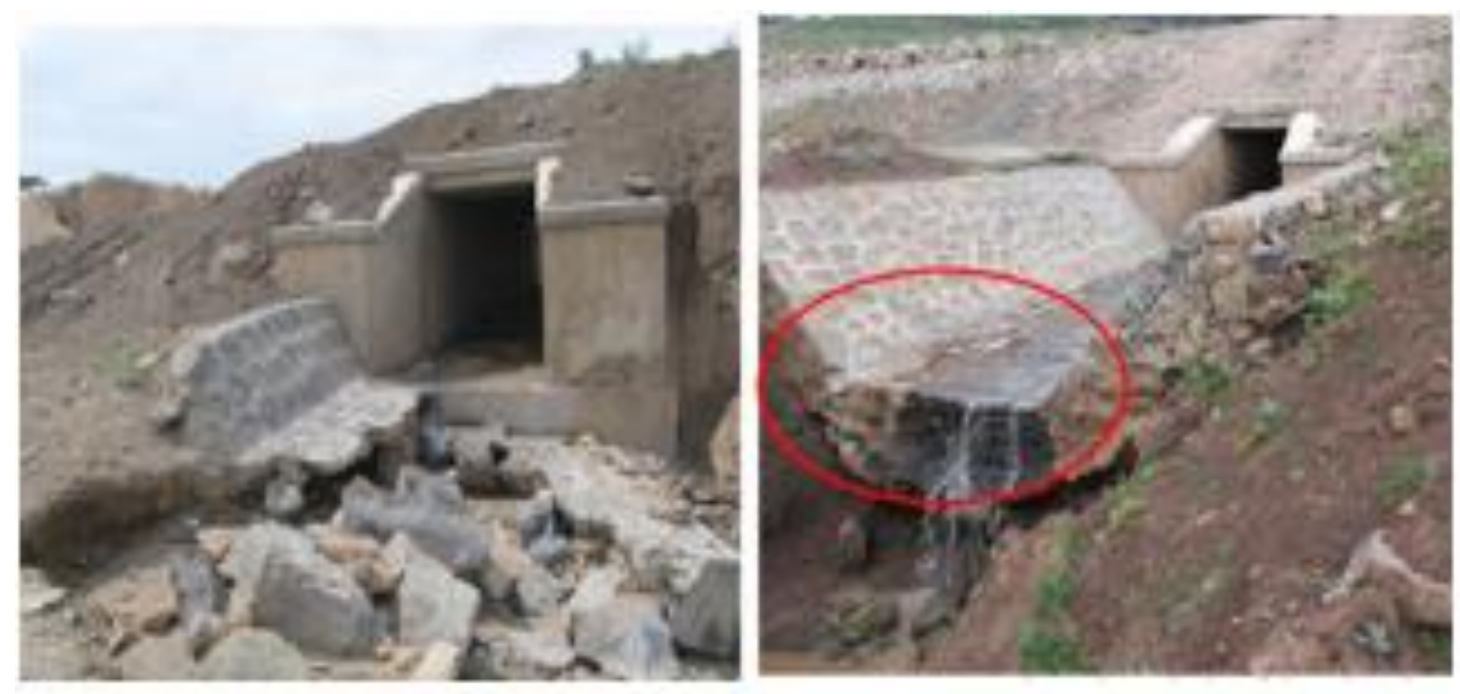

Figure 1: Outlet Scour of culvert (site report, 2013)

According to site investigation report, there is many failures of drainage facilities along the railway alignment from Sebeta - Mieso. The location, alignment, size, channel diversion and number of structures are not properly considered and supported by hydrological and hydraulics analysis [1]. This problem leads to inlet and outlet scour, water ponding, embankment cracking, etc. The hydraulic structures presented below are samples of different types of failures observed along new railway line. 


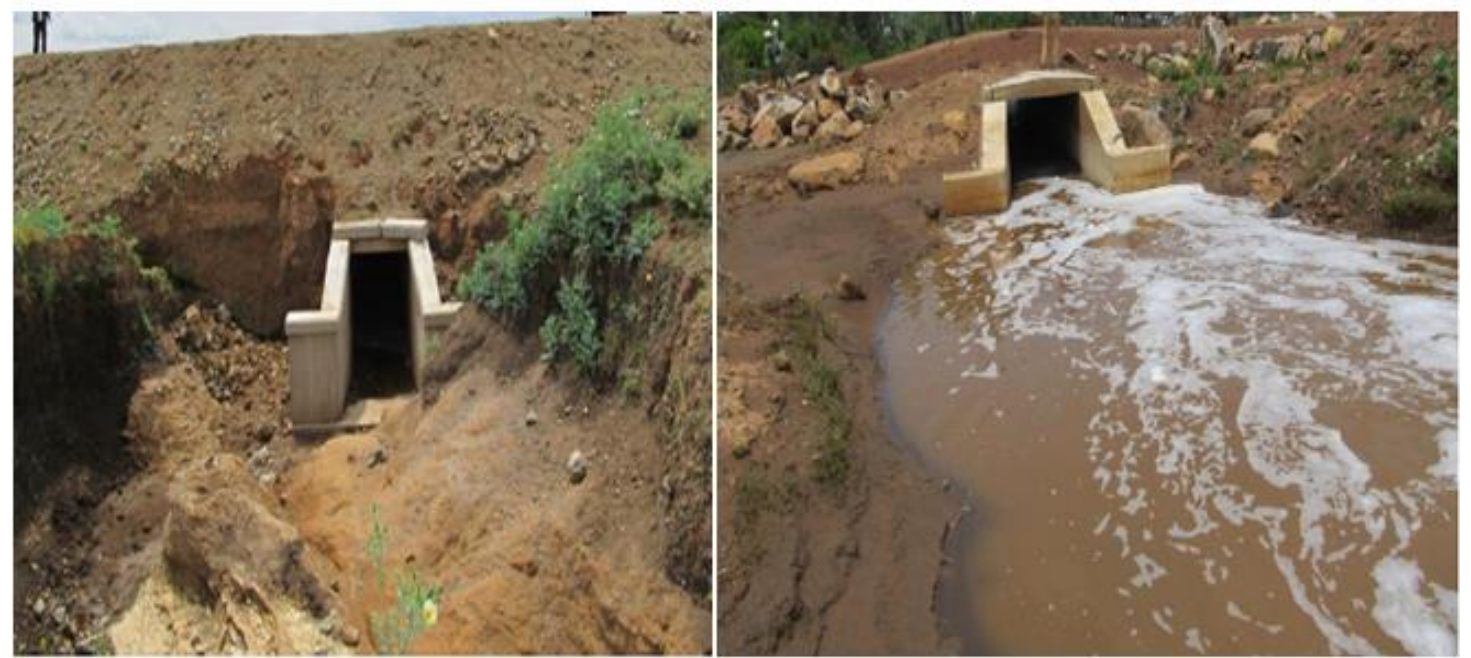

Figure 2: Inlet scours and ponding (Ethiopian Railway Corporation, site report 2013)

According [4], the main causes for failure of the drainage structures are due to the following factors: 1) Basin Characteristics: Size, shape, land use, geology, soil type, surface infiltration and storage etc. 2) Stream channel Characteristics: geometry and configuration, natural and artificial controls, channel modifications, aggradations, degradation and debris. 3) Flood plain characteristics. 4. Meteorological characteristics

Saving rail track from continues maintenance, using natural and human recourses properly, creating the environment friendly and hypothesizes suitable design and construction methods that fit Ethiopian environmental condition are just some of them. Developing hydrologic and hydraulic analysis for railway/ highway drainage system is used to build efficient hydraulic structure that will bring many benefits from economic and functional perspectives [5]. Hydrologic and hydraulic analysis for railway drainage system seems too easy but plays great role in safety, efficiency and effectiveness of rail road, generally the country's development as the whole.

The main objective of the study is to check adequacy of Akaki River crossing Bridge of new railway line from Sebeta to Djibouti by under taking hydrological and hydraulics analysis and to ensure that drainage structures are designed to minimize future maintenance requirements and provide its service efficiently through its life time.

Developing hydrological models for the catchment area, conducting hydrological analysis, Analyzing rainfall runoff characteristics of the catchment, calibrating and validation of hydrological modelling and developing hydraulics models of the reach and bridge are some of specific objective performed in this study.

The Akaki river catchment is located along the North eastern to south eastern of Addis Ababa between $8^{\circ} 46^{\prime} 0^{\prime}$ ' $-9^{0} 14^{\prime} 10^{\prime}$ ' $\mathrm{N}$ latitude and $38^{\circ} 34^{\prime} 15^{\prime}$ ' $-39^{\circ} 04^{\prime} 16^{\prime}$ 'E longitude. It is surrounded to the north by Intotohill,Alaltu, Chancho and Sonkole, to the west by Ejersa and to the east by Lencha, Meta Chene Mt. Yerer, Tulu Dimtu villages. This catchment covers most of Addis Ababa city which has a total area of about $894 \mathrm{~km} 2$ 
The Railway alignment, from Sebeta- Mieso, transverses different topographical and hydro geological condition in which it crosses swampy and low land areas at Akaki Beseka. At this location quantity of surface water come from the catchment is critical issues for the provision of hydraulic structures that can safely convey it. The Akaki catchment is an integral part of the evolution and development of Ethiopian showa plateau and rift valley system. The catchment is covered by volcanic rock over laying by fluvial and residual soil in which black cotton soil is the most dominant one [4].

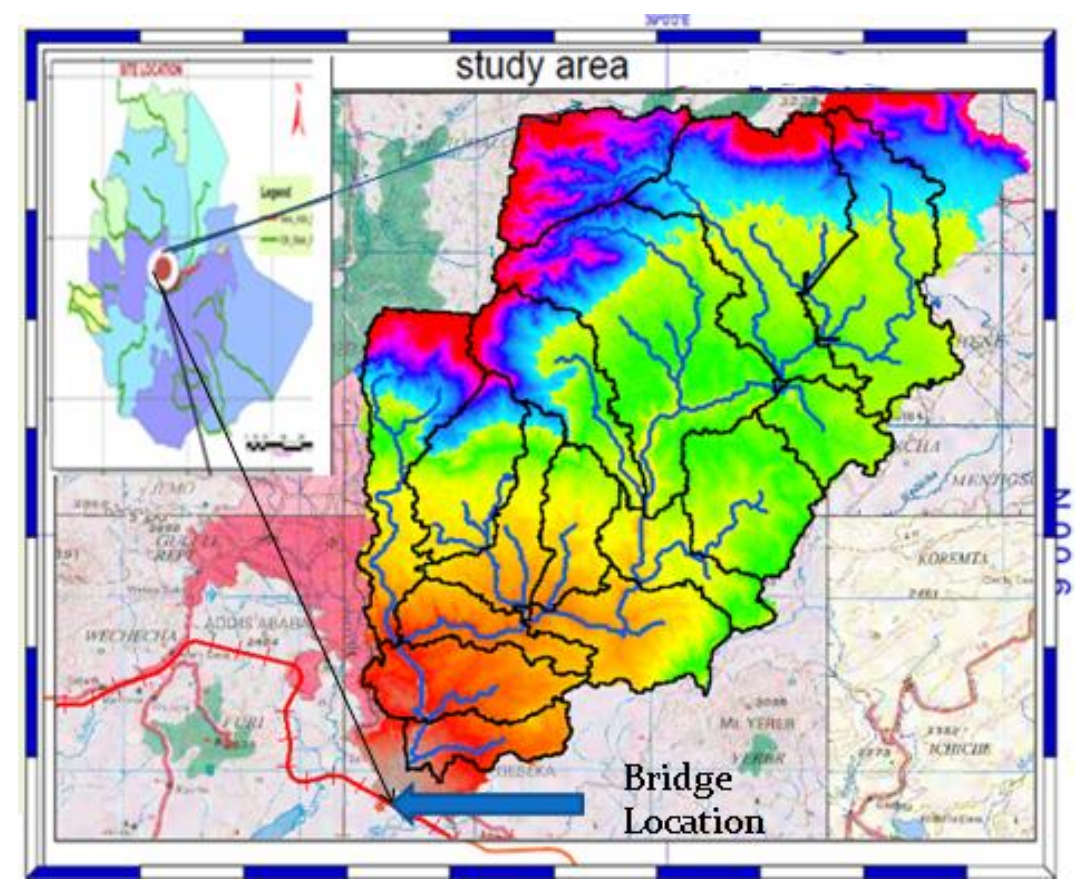

Figure 3: Study area location

The soil types that dominantly cover the catchment have been divided into nine classes as shown in figure below. It includes; calcic xerosols, chromic cambisols, chromic luvisols, chromic vertisols, eutricnitisols, leptosols, orthicsolonchaks, pellicvertisols and verticcambisols

\section{Methods and Methodology}

Data collection: For this study primary data such as Rainfall records of different station, river cross section survey and Observed stream flow data of Akaki River were collected. Bridge structure detail drawing, 30x30 resolution DEM, and Land use and soil characteristics of the catchment area are some secondary data collected for the study.

\subsection{Hydrological Model}

The hydrological model of study used to determine peak flow [2]. U.S. Soil Conservation Services (SCS) Unit hydrograph method was employed to estimate the design discharge depending on the size of catchments area. Frequency analysis was also used to compute the design flood by using gauged stream flow data. The quantities of design rainfall were estimated by using the applicable software whereas design flood was estimated separately for comparison purpose. Hydrologic 
modeling and analysis of this study was accomplished by software's like Global Mapper, Arc Hydro Tools, and HEC- Geo HMS with the help of Arc GIS and HEC-HMS programs.

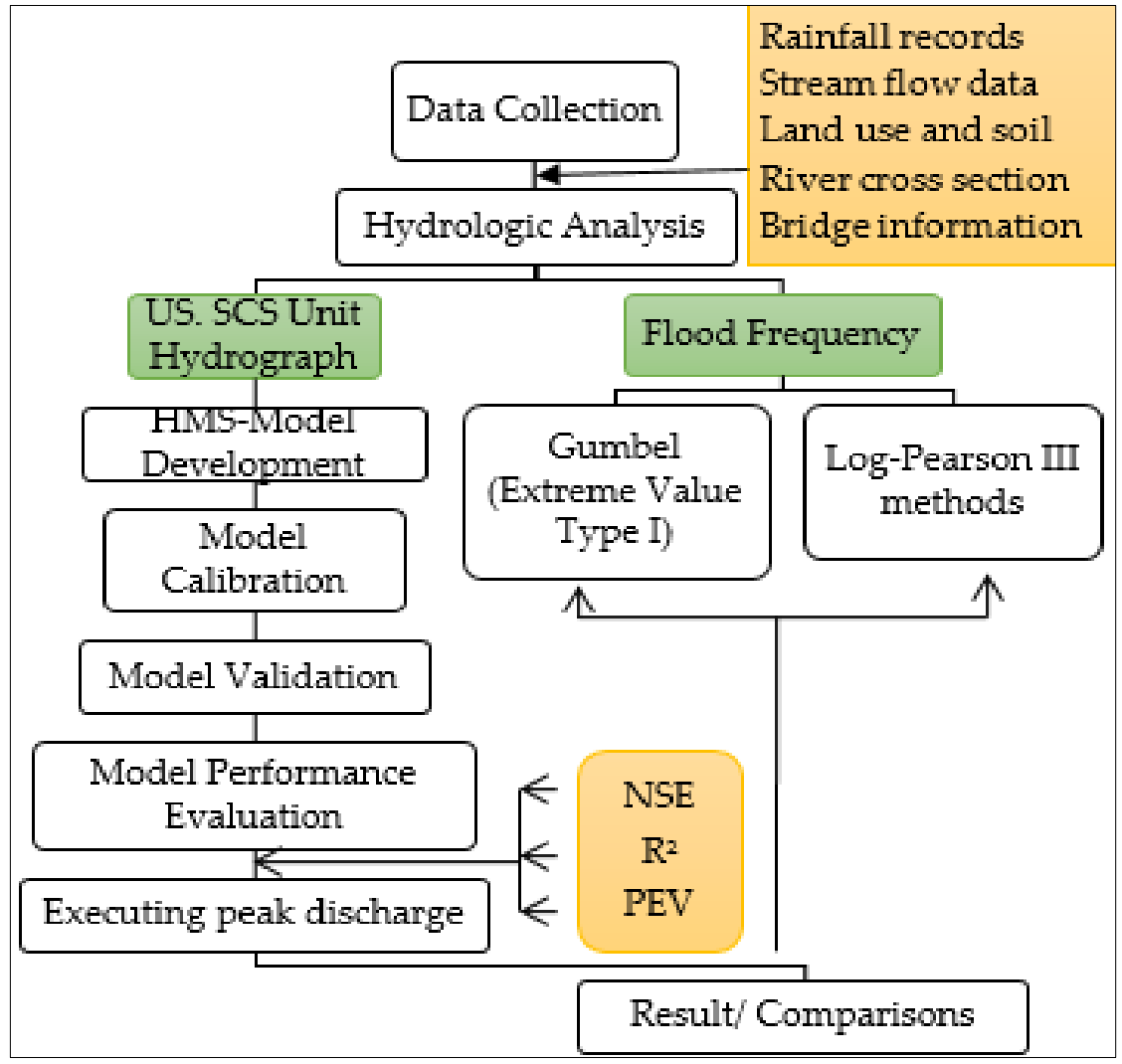

Figure 4: Hydrologic study flow chart

\subsubsection{Soil Conservation Services (SCS) Unit hydrograph Method}

SCS unit hydrograph is the most commonly used rainfall-runoff model for larger catchment area that gives reliable design discharges. SCS model has parameters which depend on climate and morphological condition [2]. SCS unit hydrograph analysis of this study was accomplished by HEC-HMS software.

\subsubsection{HMS-Model Development Using Geo-HMS}

HEC-GeoHMS is a program that works with Arc GIS (for this case, version10) used to create input files for hydrologic modeling HEC-HMS. It transforms spatial information to model files for HECHMS. Arc GIS has a capability of data processing and coordinate transformation which results DEM [13]. HEC-GeoHMS operates on the DEM to delineates sub basins and hydrologic inputs like longest flow path, centroids, river and basin slopes, etc. To accomplish this, HEC-GeoHMS has different components in which each steps should followed sequentially. Terrain processing involves using the DEM to create a stream network and catchments. 


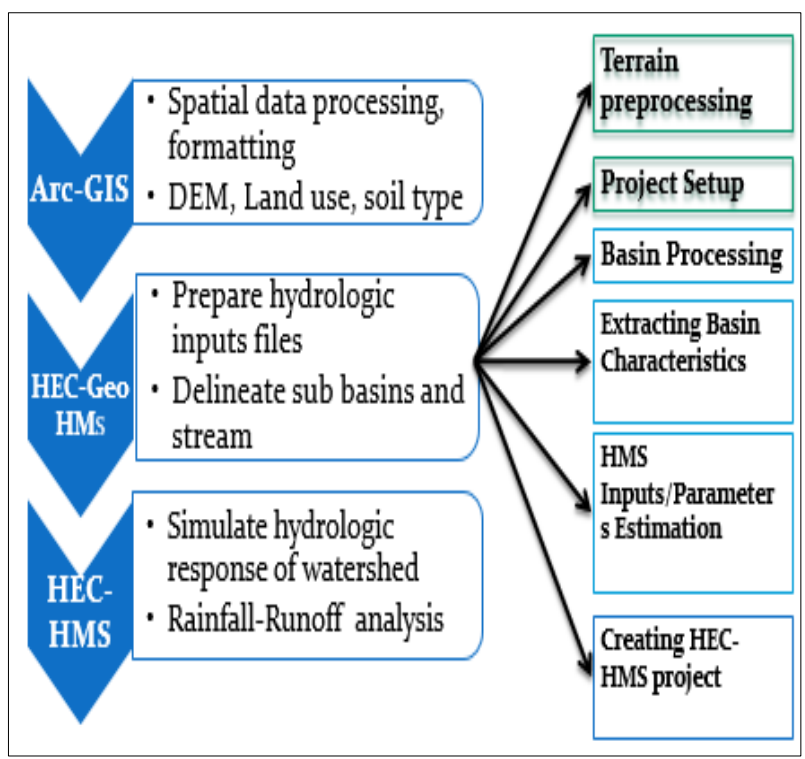

Figure 5: Hydrological Model Development

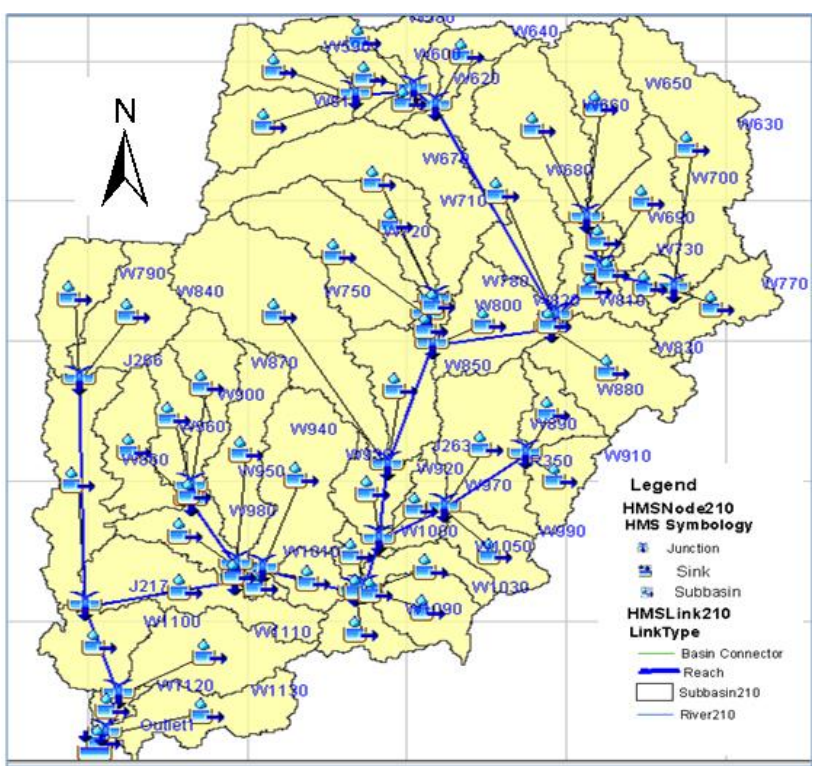

Figure 6: Created HEC- HMS project

\subsubsection{Flood Frequency Methods}

Using stream flow data of Akaki River Gumbel (Extreme Value I) and Log-Pearson III methods were used to estimate the design flood.

\section{Gumbel (Extreme Value Type I)}

The following expression is used for the computation of design flood using Gumbel method [2].

$X_{T}=\bar{X}+K_{T} S$

$$
\begin{aligned}
& \text { Where, KT = frequency factor for each return period, } \\
& \begin{array}{l}
\mathrm{S}=\text { standard deviation of stream flow } \\
\mathrm{X}=\text { mean of stream flow } \\
\mathrm{XT}=\text { design flood flow for a given return period. }
\end{array}
\end{aligned}
$$

But, KT which is the frequency factor for return period, was computed for corresponding return periods using Gumbel's distribution as given by the expression;

$K_{T}=-\frac{\sqrt{6}}{\pi}\left\{0.57721+\ln \left[\ln \left(\frac{\mathrm{T}}{\mathrm{T}-1}\right)\right]\right\} \quad$ Where $\mathrm{T}=$ Return period

\section{Log-Pearson III methods}

The Log Pearson III method is also used for the computation of design flood frequency in addition Gumbel (extreme value) Method. It is the most reliable method for stream gage data of at least 25 years. The method defined by three standard statistical parameters: the mean, standard deviation and coefficient of skew [2]. Formulas for the computation of these parameters given below:

$\log \mathrm{Q}=\operatorname{Avg}(\log \mathrm{Q})+\mathrm{KS}$

Where $\mathrm{k}=$ frequency factor, $\mathrm{s}=$ Standard deviation 


\subsection{Hydraulic Modelling}

Bridges are one of hydraulic structure that has to be designed hydraulically to accommodate the peak flood without excessive restricting the flow of the stream or incurring damage either to the structure or the surround land [11]. Manning's Formula, HEC RAS, ISIS and Hy8 programs are used to design or check cross hydraulic structures. Hydraulic modeling and analysis of this study was simulated by HEC RAS software application. River cross section and stream slope data are used in HEC-RAS.

The following steps can be used to analyze simple culvert or bridge using geometric and flow data's.

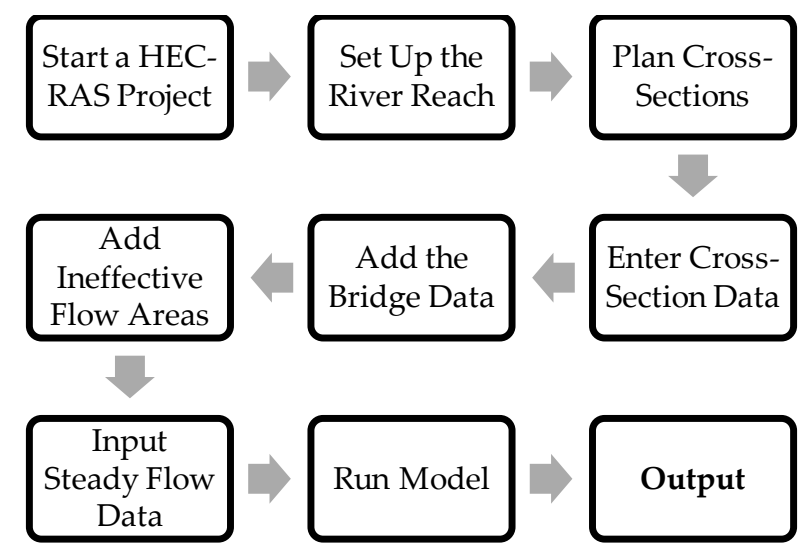

Figure 7: Hydraulic modelling process using HEC RAS

\section{Analysis and Findings}

\subsection{Hydrologic Analysis}

The hydrologic analysis should be to derive the maximum reliable discharge for a given waterway for a specific design period. The catchments area, slope, soil type, and vegetation, intensity of rainfall and duration of storm are those factors which affect the maximum discharge.

Depending on size of catchments area and availability of hydrological data, SCS Unit hydrograph rainfall-runoff model and frequency analysis method were used to compute the design flood of gauged Akaki stream. Values of the two methods were computed and compared with design peak flow.

\subsubsection{HEC-HMS Model Calibration}

The model evaluation procedure includes sensitivity analysis, calibration and validation. The sensitivity analysis of the model was performed to determine the important parameters which needed to be precisely estimated to make accurate prediction of basin yield [7].

HEC-HMS has many parameters associated with stream flow calibration. These are sub-basin parameters used in loss method, transform method, base flow method and river routing method. 
The values of each parameter were initially specified from various watershed and channel characteristics to estimate runoff and routing hydrograph. Their actual values were obtained by trial-and-error method and automatic optimization algorithm built in HEC-HMS with observed flow data [19].

For this case observed stream flow data of Akaki River for a period of 1/01/1981-31/12/2004 GC was used for model calibration and validation. The observations in the time-period (1981 to 1995) were used for calibrating the model and the data from the time-period (1995 to 2004) were used to validate the model.

The automated calibration procedure in HEC-HMS was used an iterative method to minimize an objective function[14]. HEC-HMS program is equipped with the feature that optimizes the parameters following the following process.

\section{Calibration Results}

The effectiveness of calibration was evaluated by comparing simulated peak flow and total volume with measured stream flows. After many trials the following Calibration parameters and calibration results were obtained.

Table 1: Calibration result

\begin{tabular}{|c|c|c|c|}
\hline Measure & Simulated & Observed & Percent difference \\
\hline Total volume (MCM) & 65118.7 & 52266.3 & 24.6 \\
\hline Peak Flow (m3/s) & 512.1 & 573.6 & -10.7 \\
\hline Time of peak & $31 \mathrm{Aug} 1993$ & $31 \mathrm{Aug} 1993$ & \\
\hline
\end{tabular}

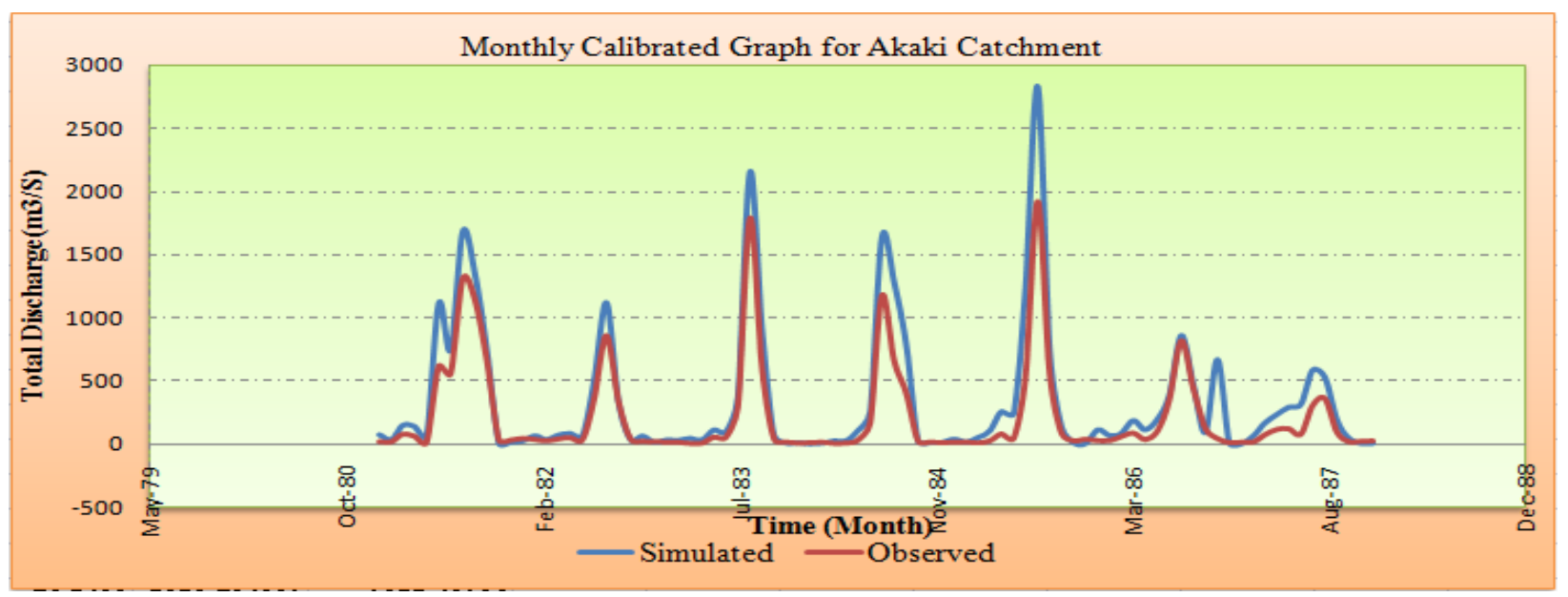

Figure 8: Calibration Hydrograph comparison of simulated and observed flow at outlet (sample taken from study year)

\subsubsection{Model Validation}

Model validation was used to determine the effectiveness of the calibrated parameters in sub basins to predict the flow discharges. For this study, the calibrated HEC-HMS model was then used to estimate daily stream flow from the sub basins for the period 1/01/1995 -31/12/2004. The observed and simulated hydrographs are presented below. 
Table 2: Validation result

\begin{tabular}{|l|l|l|l|}
\hline Measure & Simulated & Observed & Percent difference \\
\hline Total volume (MCM) & 88571.78 & 74426.2 & 19.0 \\
\hline Peak flow (m3/s) & 678.1 & 693.6 & -2.2 \\
\hline Time of peak & 11 Aug1999 & 11 Aug1999 & \\
\hline
\end{tabular}

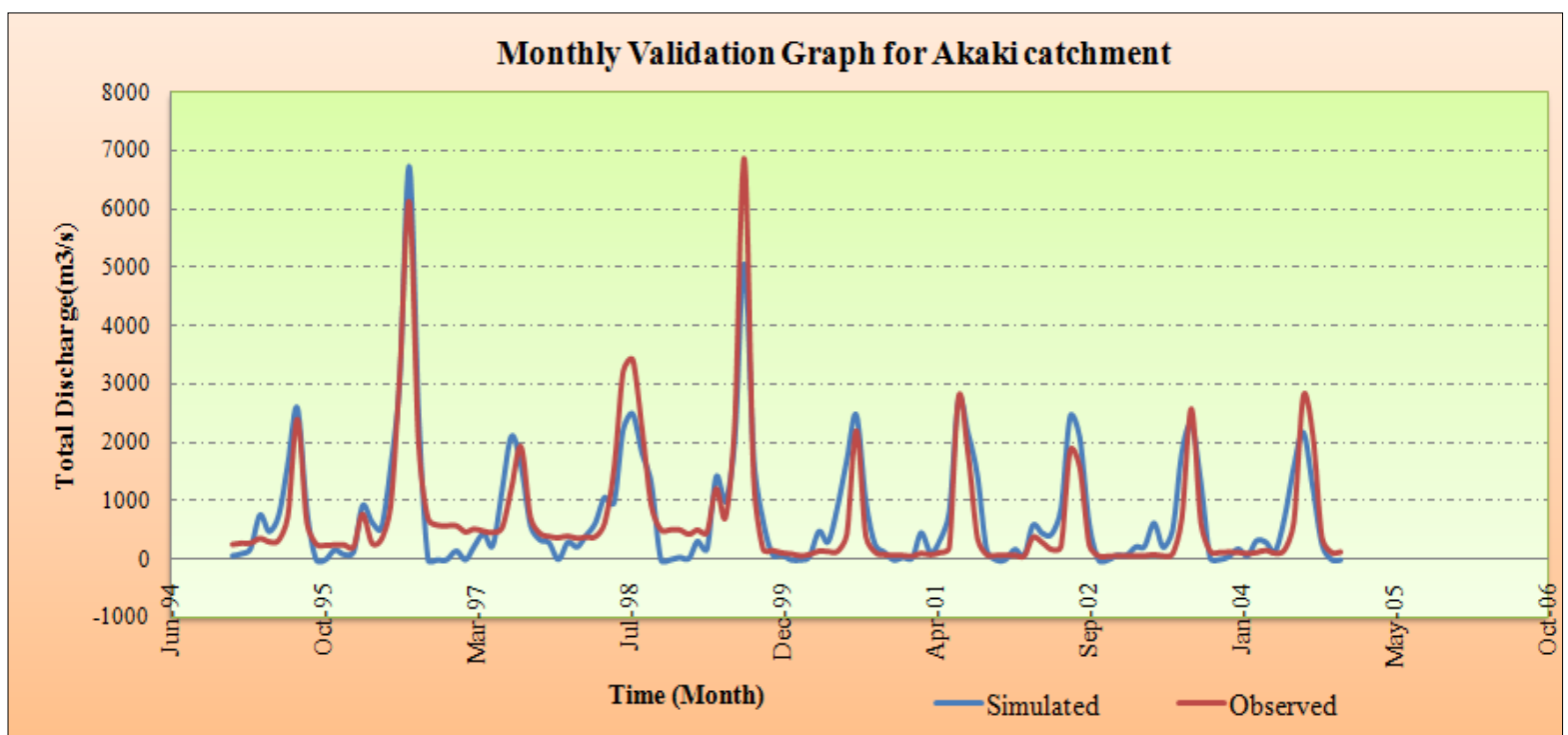

Figure 9: Validation Hydrograph of simulated and observed flow (sample of flow from19952004)

\subsubsection{Model Performance Evaluation}

The performance evaluation of hydrologic model is commonly used to know efficiency of the model to provide accurate result through comparisons of simulated and observed variables. According to [10] the reasons why hydrologists need to evaluate model performance is that, to provide a quantitative estimate of the model's ability to reproduce historic and future watershed behavior and to compare current modeling efforts with previous study results.

Different efficiency criteria are used to evaluate performance of hydrologic models; such as the Nash-Sutcliffe efficiency, coefficient of determination and volume difference are frequently used in hydrologic modeling.

\section{Nash-Sutcliffe efficiency (NSE)}

The efficiency NSE is defined as one minus the sum of the absolute squared differences between the predicted and observed values normalized by the variance of the observed values during the period under investigation [10]. It is given as;

$\mathrm{NSE}=1-\frac{\sum_{i=1}^{n}\left(O_{i}-P_{i}\right)^{2}}{\sum_{i=1}^{n}\left(O_{i}-\bar{O}_{i}\right)^{2}} \quad$ Where, with $\mathrm{O}$ observed and $\mathrm{P}$ predicted values

The range of NSE lies between 1.0 (perfect fit) and negative infinity. 


\section{Coefficient of determination R2}

The coefficient of determination $\mathrm{r} 2$ is defined as the squared value of the coefficient of correlation according to Bravais-Pearson [10]. It is calculated as:

$$
r^{2}=\left(\frac{\sum_{i=1}^{n}\left(O_{i}-\bar{O}_{i}\right)\left(P_{i}-\bar{P}_{i}\right)}{\sqrt{\left(O_{i}-\bar{O}_{i}\right)^{2}} \sqrt{\left(P_{i}-\bar{P}_{i}\right)^{2}}}\right)
$$

The range of $\mathrm{r} 2$ lies between 0 and 1 which describes how much of the observed dispersion is explained by the prediction. A value of zero means no correlation at all whereas a value of 1 means that the dispersion of the prediction is equal to that of the observation.

\section{Percentage error Volume (PEV)}

The PEV value measures the deviation between the simulated and the observed volume of stream flow. It is calculated as;

$$
P E V=\frac{V_{o}-V_{c}}{V_{o}} \times 100
$$

Where Vo and Vc are the observed and computed runoff volume, respectively.

Using the above efficiency measures, the performance of this study was determined as shown in table below for both calibration and validation.

Table 3: Performance measures of the model for the calibration and validation years

\begin{tabular}{|c|c|c|c|c|c|}
\hline \multicolumn{2}{|c|}{$\begin{array}{c}\text { Model performance for } \\
\text { Akaki Catchment }\end{array}$} & $\begin{array}{c}\text { Nash-Sutcliffe } \\
\text { Efficiency (NSE) \% }\end{array}$ & $\begin{array}{c}\text { Coefficient of } \\
\text { Determination (R2) \% }\end{array}$ & $\begin{array}{c}\text { Relative Volume } \\
\text { error \% }\end{array}$ \\
\hline \multirow{2}{*}{$\begin{array}{c}\text { Akaki } \\
\text { Catchment }\end{array}$} & Daily & Calibration & 52.6 & 57.2 & 24.6 \\
\cline { 2 - 5 } & & Validation & 48.2 & 68.7 & 19.0 \\
\cline { 2 - 5 } & \multirow{2}{*}{ Monthly } & Calibration & 77.8 & 83.02 & 19.5 \\
\cline { 2 - 5 } & & Validation & 73.5 & 87.33 & 21.5 \\
\hline
\end{tabular}

According to Motovilov et al., 1999 sited in [7], simulation results are considered to be good for values of NSE greater than or equal to 0.75, while for values of NSE between 0.75 and 0.36 the simulation results are considered to be satisfactory.Thus, the performance measures, NashSutcliffe model efficiency values for monthly flow were slightly well for both the calibration and validation. This indicates that there is close agreement between observed and simulated runoff. The value of the coefficient of determination $\mathrm{r} 2$ ranges between 57.2-87.33\%, which is greater than zero less than one. As described before the value of coefficient of determination $\mathrm{r} 2$ ranges between 1(best fit) and 0 (no correlation between observed and simulated flow).

The PEV values for the catchment were found to lie between 19-24.6\%. The acceptable level of PEV for hydrologic simulations is $\pm 20 \%$. [7]. Thus, the PEV values of the Akaki catchment are close to acceptable levels of accuracy $( \pm 20 \%)$ for simulations models for validation and calibration years. 
Generally, the performance evaluation shows that, HEC-HMS model developed for Akaki catchment was acceptable and reasonably satisfactory that can now be used for hydrologic analysis.

\subsubsection{Peak discharge using Calibrated and Validated HMS Model.}
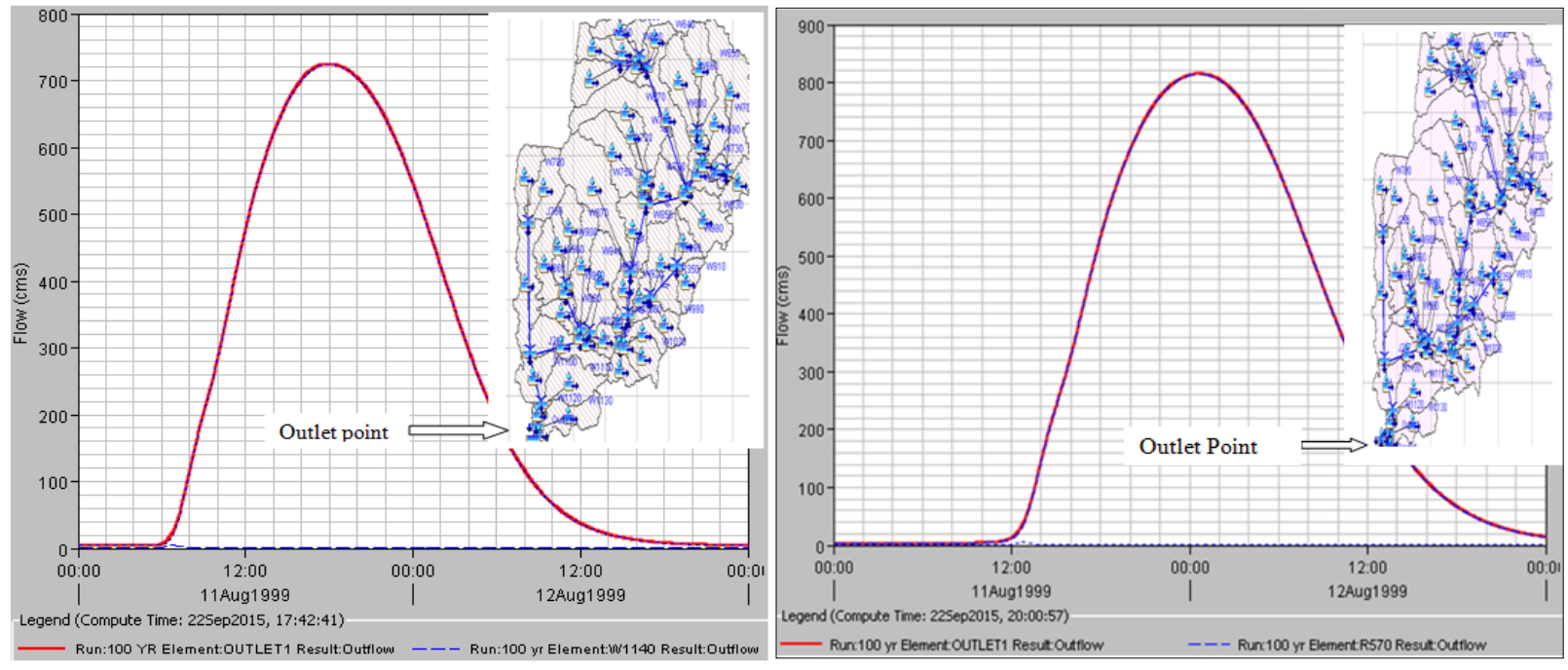

Figure 10: Outlet output hydrograph for $1 \%$ and $0.2 \%$ exceedance probability

The frequency storm, which uses statistical precipitation data, was used in model to produce peak discharge for 50 and 100 return periods (exceedance probability) [11]. The result for both 50 and 100 year return periods were found $727.1 \mathrm{~m} 3 / \mathrm{s}$ and $815.6 \mathrm{~m} 3 / \mathrm{s}$ respectively.

\subsubsection{Flood Frequency Analysis}

The result of stream flow data analysis by using Log-Pearson III and Gumbel methods are presented below.

Table 4: Flood Frequency Analysis Result

\begin{tabular}{|c|l|l|l|l|}
\hline \multirow{2}{*}{ Method Of Computation } & RP & Mean & STDEV & Design Flood \\
\cline { 2 - 5 } & Year & $\mathrm{m} 3 / \mathrm{s}$ & & $\mathrm{m} 3 / \mathrm{s}$ \\
\hline \multirow{2}{*}{ Gumbel (Extreme Value Type I) } & 50 & 278.386 & 163.523 & 711.826 \\
\cline { 2 - 5 } & 100 & 278.386 & 163.523 & 803.7093 \\
\hline \multirow{2}{*}{ Log-Pearson -III Distribution } & 50 & 278.386 & 163.523 & 685.5362 \\
\cline { 2 - 5 } & 100 & 278.386 & 163.523 & 753.6776 \\
\hline
\end{tabular}

Comparing SCS Unit hydrograph and flood frequency analysis, SCS method is slightly greater i.e. $727.1 \mathrm{~m} 3 / \mathrm{s}$ and $815.6 \mathrm{~m} 3 / \mathrm{s}$ for 50 and 100 years return period respectively that used to check hydraulic capacity of the bridge with the help of HEC-RAS program. 


\subsection{Hydraulic Analysis and Result}

The hydraulic analysis for the river consisted of modelling the flow characteristics using the HECRAS version 4.1.0. Physical characteristics of the river (cross section), manning's coefficient, contraction and expansion coefficients, ineffective flow area and quantity of flow are important inputs of HEC-RAS program.

\subsubsection{Bridge Hydraulic Modeling}

The basic computational procedure for the HEC-RAS program is water surface profiling based on energy equation. Energy losses are evaluated by friction (Manning's equation) and contraction/expansion. The momentum equation is utilized in situations where the water surface profile is rapidly varied, such as at bridges Error! Reference source not found..

HEC-RAS program has the ability to analyze water profile near and inside bridge for different flow type. These types of flow are; low flow (Class A, B, and C), high flow and combined flow methods Error! Reference source not found..

Low flow occurs when the water flow only through the bridge opening and considered as an open channel flow i.e. when the water surface does not exceeds the highest point of low cord on the upstream of the bridge [19]. HEC-RAS program uses Momentum equation to identify Class A, B or $\mathrm{C}$. If the momentum downstream of the bridge is greater than the critical depth momentum inside the bridge, the flow is considered subcritical (Class A). If the momentum downstream is less than the momentum at critical depth, then it is Class B and assumed that the flow will pass through critical depth and a hydraulic jump will occur at downstream. Class C- the profile is considered completely supercritical through the bridge.Error! Reference source not found.

For this study case combined flow method is more applicable to determine water surface profile, because the aim of this work is to check whether the computed flow is safely pass under bridge (low flow) constructed or overflow (high flow) would occur for specified flood return periods. Accordingly, the normal water level which corresponds to flood with 50/100 years design period has been taken as High Water Mark (HWM) was obtained.

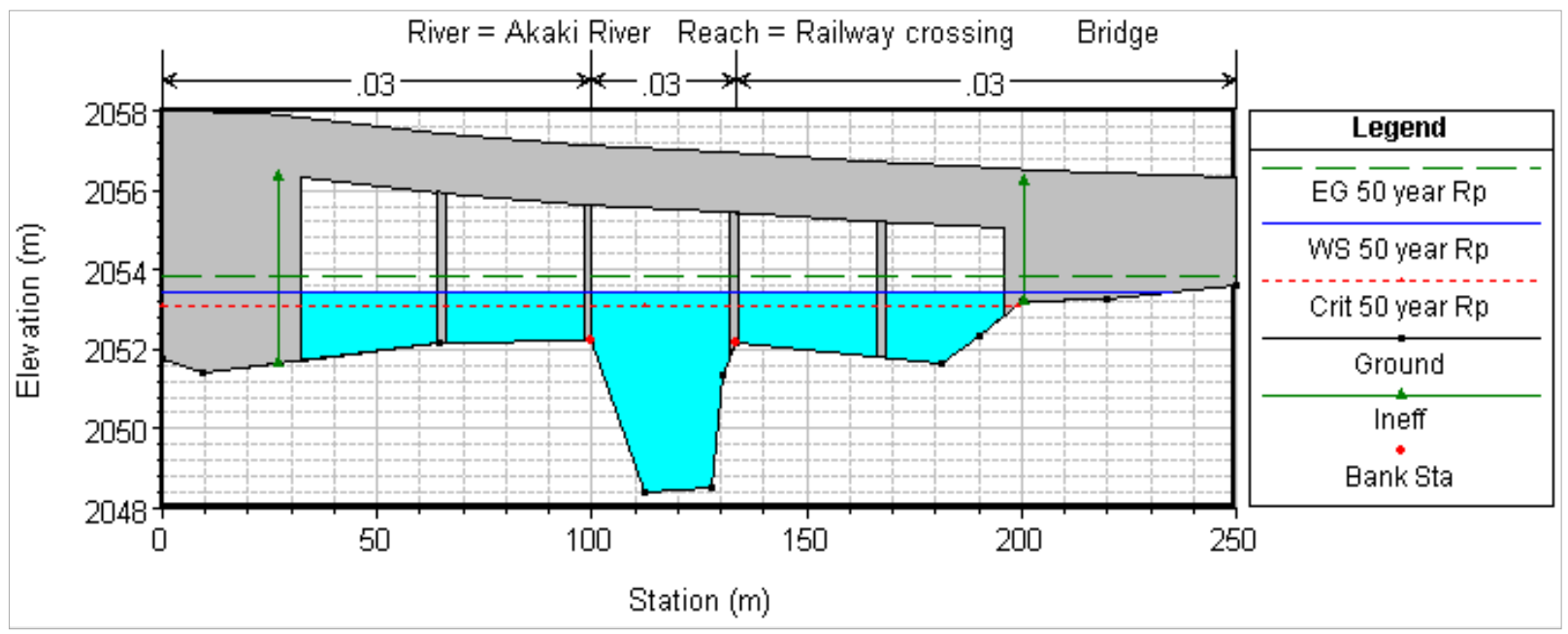




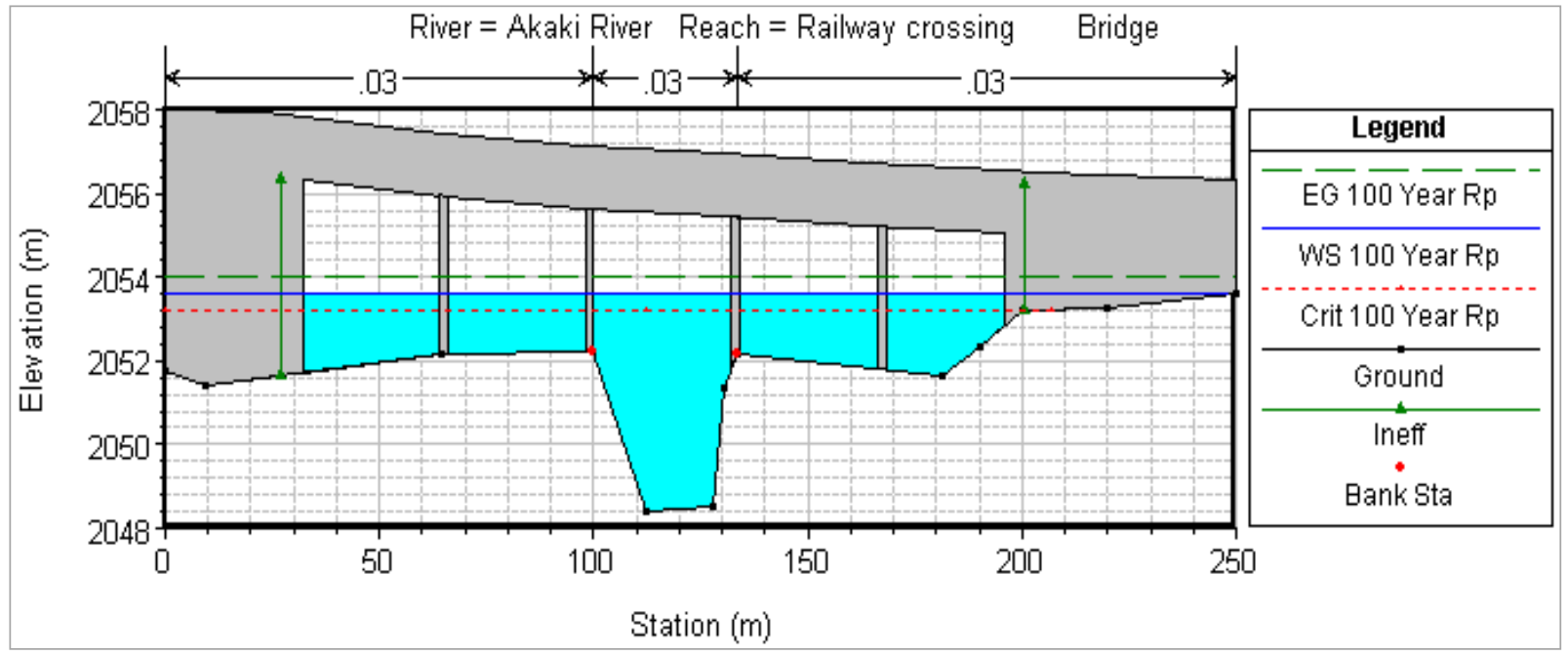

Figure 11: HEC - RAS 50/100 years design flood level at Bridge cross section
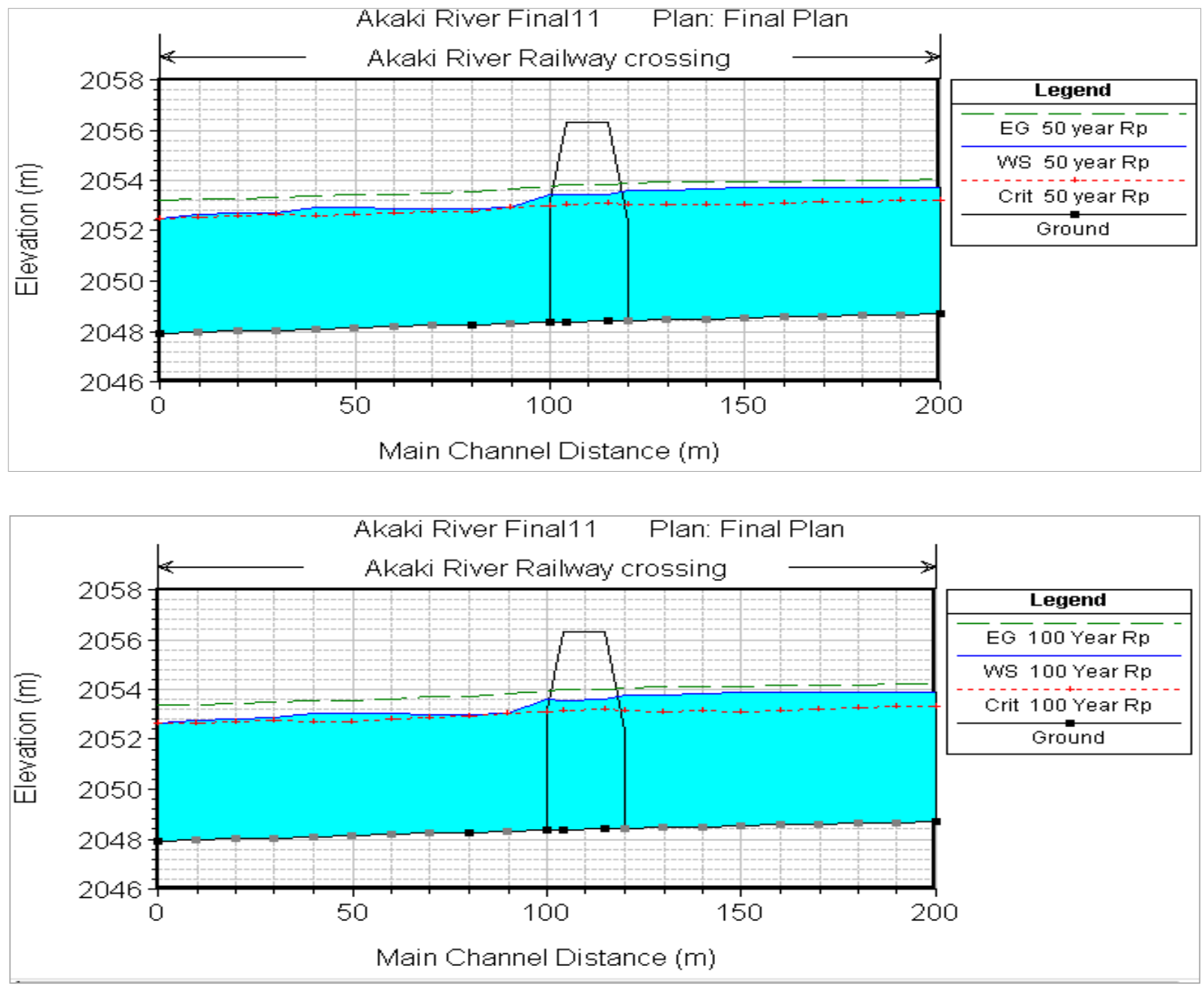

Figure 12: HEC - RAS 50/100 years design flood level profile 


\section{Conclusions}

Adequacy of hydraulic structure highly subjected detail hydrological and hydraulic analysis. This study was also under gone both hydrological and hydraulic analysis of Akaki River Bridge. A newly constructed Akaki Railway Bridge, which has clear span length of $163.84 \mathrm{~m}$ $(32.81 \mathrm{~m}+32.74 m+32.74 m+32.74 m+32.81 \mathrm{~m})$, was checked by using the 50 years and 100 years return period peak discharge.

In order to develop hydrologic and hydraulic model of the catchment and reach, different programs; such as HEC-Geo HMS with Arc GIS, HEC-HMS, HEC-RAS were used. Detailed hydrological assessment had been undertaken with different method such as SCS unit hydrograph with the help of calibrated and validated HEC-HMS model, and Flood frequency analysis methods Based on the HEC- RAS result, this bridge has sufficient opening size that can safely passes computed peak discharge for 50/100 years return period respectively. The minimum lower cord elevation of the bridge is $2056.33 \mathrm{~m}$, whereas the maximum water surface elevation at bridge location are $2053.9 \mathrm{~m}$ and2054.08m for 50/100 year peak flow respectively i.e. greater than $2 \mathrm{~m}$ clear space above water surface level. According to Akaki railway bridge detailing data collected, the bridge span and opening space is designed according to the landform (alignment) of the location i.e. geometrical alignment railroad determine span length and opening size of the bridge rather than its hydrology. That is why the opening space is adequate to pass peak discharge determined during this study period.

The hydraulic calculation confirmed that Akaki River Bridge can give its full service efficiently for the return period specified. Adequacy of this bridge was evaluated depending on currently available data's

Finally, flow velocity is higher at bridge location than specified flow speed for earthen material, thus, it is important to provide structures like masonry retaining wall, launching aprons at the bridge location and also provide energy dissipation mechanisms such as cascading of the channel.

\section{Acknowledgements}

I would like to express my genuine gratitude and appreciation to my advisor Dr.Ing. Dereje Hailu for his encouragement, valuable guidance and support during my studies. I highly appreciate his constructive criticism and valuable advises which helped me to locate this research in the right direction. I benefited a lot from discussions I had with him.

I would like to express my Sincere and heartfelt gratitude to the Ethiopian Railway Corporation for giving sponsorship and granting me the opportunity to pursue this course of study without which I would not have realized my dream to further my studies.

My gratitude also goes to my former supervisor Dr. Manaye Ewnetu for his excellent guidance and encouragements for laying me a sound foundation on modelling during my course study, kind guidance, valuable comments from the start of title selection and providing me data and necessary information. 


\section{References}

[1] AREMA, (2010), Manual for Railway Engineering, Volume 4, Systems Management Water and Wastewater Compliance

[2] Ven Te Chow, et.al. (1964), Handbook of Applied hydrology

[3] Manaye Ewunetu, (2013); Sebeta to Adama Double Track Railways Project Site Visit Investigation Report and Recommended Rehabilitation Works. Ethiopian Railways Corporation. Addis Ababa, Ethiopia

[4] Beza Nigussie, (2010); Investigation of cause of failures of Highway cross drainage Structures (Case study on Raya River Bridge). Msc thesis, Addis Ababa University, Addis Ababa

[5] Bisrat Temesgen, et.al. (2015); Investigating Highway Drainage Problems in the Sile River Bridge, South, Ethiopia. www.jmest.org

[6] Alema Tesfaye, (2009); Steady - state ground water flow and contaminants transport Modeling of Akaki Well field and its surrounding catchment (Addis Ababa University, Addis Ababa). Msc Thesis,

[7] D. Roy, S. Begam, et.al.(2013); calibration and validation of hec-hms model for a river basin in eastern India. www.arpnjournals.com

[8] Arlen D.Feldman, (2000); Hydrologic Modeling System, Technical Reference Manual. US Army Corps of Engineers, Hydrologic Engineering Center

[9] William A. Schanffenberg and Matthew J. Fleming, (2010); Hydrologic Modeling System, User's Manual. US Army Corps of Engineers, Hydrologic Engineering Center

[10] P. Krause, D. P. Boyle, et.al. (2005); Comparison of different efficiency criteria for hydrological model assessment. Advances in Geosciences, 5, 89-97, 2005

[11] Ethiopian Roads Authority. (2013). "Drainage Design Manual", Federal Democratic Republic of Ethiopia.

[12] Denali Park, AK 99755(2013); Hydraulic Mapping and Modeling. Fairbanks Soil and Water Conservation District Fairbanks, Alaska 99709

[13] K. Westerberg, J.-L. Guerrero, P. M. Younger, et.al. (2011); Calibration of hydrological models using flow-duration curves. Hydrology and Earth System Science

[14] Matthew J. Fleming, James H. Doan, (2013). Geospatial Hydrologic Modeling Extension: US Army Corps of Engineers, Hydrologic Engineering Center

[15] Matthew J. Fleming, (2010); Hydrologic Modeling System, Quick start guide. US Army Corps of Engineers, Hydrologic Engineering Center

[16] H. L. Zhang, Y. J. Wang, et.al. (2013); The effect of watershed scale on HEC-HMS calibrated parameters: a case study in the Clear Creek watershed in Iowa, US. Hydrology and Earth System Science

[17] David Ford, Nathan Pingel, J.J. DeVreis, (2008), Hydrologic Modeling System, Application Guide. US Army Corps of Engineers, Hydrologic Engineering Center

[18] Gray, W. Brunner. (2006). "HEC RAS, River Analysis System Reference Manual" U.S Army corps of Engineers Hydrologic Engineering Center

[19] Melih Yanmaz and Feridun Coskun, (2014); Hydrological Aspects of Bridge Design, Middle East Tech. Univ., 06531, Ankara, Turkey

[20] . Joan C. Warner, Gray, W. Brunner, et.al. (2010). "HEC RAS, River Analysis System Application Guide" U.S Army corps of Engineers Hydrologic Engineering Center,

*Corresponding author.

E-mail address: yerosana7@ gmail.com 